book is new are unlikely to find a better guide to and instructor in the pathology of tumours of the nervous system.

\section{Peripheral Entrapment Neuropathies}

By Harvey P. Kopell and Walter A. L. Thompson. Pp. vii +187 , illustrated, hard cover. Robert E. Krieger Publishing Co., New York, 1976. \$13.50.

This interesting book, written by enthusiasts with great experience of the subject, is easy to read and well worth reading. In it, the authors imply that pain virtually anywhere can be caused by entrapment of some nerve somewhere along its course. Physicians and surgeons in different disciplines will learn from it of the existence of a number of otherwise unexplained painful syndromes which may affect any part of the body. The main practical problem which this gives rise to is that apparently quite often it will not result in the appearance of the expected neurological deficit. It seems therefore that only enthusiasts brave enough to explore the appropriate nerve at the expected site of entrapment will be able to reach the correct diagnosis by effecting a cure.

The rather unique experience of the authors can be gathered from the statement (p. 48) that the 'restless legs' phenomenon is probably due to 'a low grade neuropathy of the peroneal nerve' and from the description of a patient with myasthenia gravis (p. 179) whose illness caused back pain due apparently to unstable small muscle system and spasm of the larger muscle masses, was cured by the administration of prostigmine where six major spinal operations carried out previously had failed!

\section{Practice - A Handbook of Primary Medical Care}

Instalmen: IV. Edited by J. CormaCK, M. MARINKER AND D. Morrell. Kluwer-Harrap Handbooks, London, 1977. $£ 6.50$ per instalment plus special binder at $£ 1.60$ and postage. (Updating service planned to cost about $£ 6.00$ p.a.)

Previous reviews have indicated the nature and pattern of this loose-leaf General Practice Manual. In the penultimate instalment there are twelve further chapters from the main part of the book, devoted to diseases and symptoms. In addition, we received the first two chapters from Part 4. Marshall Marinker's introductory chapter to this part is on the nature of continuing care. It is a well reasoned essay about the role of the general practitioner, his place as a family doctor, his virtues and his limitations. As with the introductory chapter to the first part, this chapter is worth reading on its own account. The other chapter in Part 4 provided with this instalment is on adolescence. It, too, in its own way, is equally interesting.

The series as a whole is proving very popular both in the United Kingdom and overseas.

\section{Principles for First Aid for the Injured}

By H. Proctor AND P. S. London. Pp. xiv +284 , illustrated, hard cover. Butterworths, London, 1977. £6.25.

This third edition of a well established book on First Aid has been enlarged to encompass the recent trends in emergency care for the injured. The book has retained its basic format and deals with the principles of infection, haemorrhage, fractures and burns, as well as presenting a detailed systematic survey of injuries to different parts of the body. The book is designed for the 'First Aider' but with the rapidly changing organization of emergency work, both civil and military, the task of initiating primary treatment may fall upon doctors, nurses, ambulance men, highly trained 'paramedics' or various other organized groups. This book is clearly written, well illustrated and has concise summaries of emergency treatment after each chapter. It will appeal to all those engaged in accident work including, no doubt, medical students. Doctors working in the field may be surprised at the detailed knowledge now required by their non-medical colleagues and may well wish to use this excellent book as a guide-line for their lectures on First Aid.

\section{Prolactin and Human Reproduction}

By P. G. Crosignani and C. Robyn. Pp. vii +305 , illustrated, hard cover. Academic Press, 1977. £10.50, $\$ 20.50$.

This book contains a collection of papers presented at the eleventh International Symposium of the Serono Foundation held at Cernobbio in July 1976. The result is a comprehensive compendium concerning the many roles of prolactin in human reproduction. Unfortunately, little information is presented concerning the considerable difficulties associated with the measurement of this hormone by radioimmunoassay and no mention of possible alternative techniques. Accordingly, there is no explanation for those situations where apparently conflicting findings have been reported, e.g. the concentration of prolactin in peripheral plasma during the ovarian cycle. Notwithstanding this limitation, however, there is much convincing information on the plasma levels of the hormone throughout life and upon the origins and role of the compound in amniotic fluid. In addition, there are interesting results from studies on factors that affect the secretion of prolactin under physiological and pathological conditions. Finally, there is a section upon the characterization and management of patients with hyperprolactinaemia associated with abnormal gonadal function. The book contains many new findings and should be of particular value to practising endocrinologists or gynaecologists.

\section{Recent Advances in Surgery}

Edited by Selwyn Taylor. Pp. vii +450 , illustrated, hard cover. Longman Group, Harlow, 1977. £11.00.

The appearance of a new Recent Advances in Surgery is always greeted with a sigh of relief by surgeons, such as the present reviewer, who have to struggle to keep abreast with new techniques and advances in their own field together with progress in subjects adjacent to their speciality. In this ninth edition, Mr Selwyn Taylor, as Editor, has not failed us. With an expert touch, he has chosen subjects of the very greatest interest and he has matched this wide choice by selecting a team of a couple of dozen expert surgical teachers, pathologists and physicians as his contributors. The chapters include fundamental topics of haemostasis, immunology and parenteral nutrition as applied to surgical problems; then there is a group of 'bread and butter' items of great importance to the general surgeon, which include cancer of the rectum, acute pancreatitis and portal hypertension, and then a group of specialist items chosen for their particular current importance and which include microsurgery, coronary artery bypass, the surgery of obesity and, bring us right into the North Sea oil exploration era, the use of hyperbaric oxygen chambers in surgery. The Editor himself contributes the final chapter which sums up the present situation regarding the training of surgeons in the United Kingdom.

This is an important and welcomed volume. The chapters are interesting, well written, up to date and will each serve as a useful monograph on some of the most exciting points of progress in surgery to-day.

\section{Side Effects of Drugs Annual 1}

By M. N. G. Dukes. Pp. vii +420 , hard cover. Excerpta Medica, Amsterdam, 1977. US \$38.50, Dfl. 100.00.

The standard source for the literature on the side effects of drugs is Meyler's Side Effects of Drugs, which has reached volume VIII in covering publications up to 1975 . Whereas 
Meyler's provides an encyclopaedic survey this new publication is intended to give regular critical reviews of recent reports, starting at January 1975. The editor has chosen a team of contributors who are practising clinicians, mainly British and from the mainland of Europe; their combined efforts are undoubtedly highly successful. This initial volume provides readable, authoritative accounts of all fields of drug usage. There are useful indices to drugs, synonyms and side effects and the references are coded to indicate whether the paper is a critical review, detailed clinical report, etc.

This book can be warmly recommended as a valuable addition to the not insubstantial review literature of drug side effects for reference as an aid to keeping up to date in one's own field, and for pleasurable browsing.

\section{The Specific Treatment of Virus Diseases}

By D. J. Bauer. Pp. 194, illustrated, hard cover. MTP Press, Lancaster, 1977. £8.95.

This is an excellent review of the currently available drugs with specific antiviral activity which have relevance to clinical medicine.

Antiviral drugs have been in clinical use for approximately 15 years. At present, topical therapy is generally more satisfactory than systemic, but one hopes that more effective and less toxic drugs will be developed in the future. Recent work with amantidine hydrochloride suggests that we may be very grateful for this drug in prophylaxis and therapy in any future influenza pandemic.

Many clinicians, particularly ophthalmologists, dermatologists, neurologists and infectious disease specialists, are using antiviral drugs. They should welcome this book for its collected documentation of past experience with the drugs and for the extensive reference list.

It should prove worthwhile reading for the medical undergraduate but it is doubtful whether many students will be in a financial position to possess their own copy.

There are four chapters relating to the treatment of patients with specific virus diseases. As the book is intended fo clinicians, it seems a pity that the author has not taken the opportunity to include a little more advice on generat. management and the use of certain drugs with non-specific activity. This would, perhaps, be more relevant than some of the basic virological information which is readily availabte elsewhere.

There are few significant errors, but one is worthy of note In the list of preparations of idoxuridine, Herpid (W. B? Pharmaceuticals) is stated to contain $0.5 \%$ idoxuridine i⿱⺈ dimethylsulphoxide. This should be $5.0 \%$ idoxuridine, and as the other listed preparations are for ophthalmic use, if could have serious consequences particularly as dimethyl $\overrightarrow{0}$ sulphoxide is toxic in the eye.

The author is to be congratulated for producing a ver $\vec{\xi}$ readable and informative review of a field in which significand advances are continuing to come from his own laboratory. 하

It is recommended to all clinicians who are concerned wit the management of viral illness, and that is surely the majority.

\section{Statistics at Square One}

By T. D. V. Swinscow. Pp. vi 86, illustrated, soft cove British Medical Association, London, 1976. £1.50, \$3.7\$ including postage.

This is an excellent book that fulfils a definite need, partio cularly for the postgraduate medical student entering thebewildering world of statistics during his first research appointment. It explains the basic principles of the subject i a way comprehensible to anyone with no more than an " level training in mathematics (and that includes man w doctors!) without being patronizing. The whole approact is a logical progression from the simplest principles to the slightly more complicated. The only criticism is that the boroso could have been longer with chapters dealing with advanced statistics. One, therefore, sincerely hopes tha second volume will follow. 